\title{
O historiador mais conhecido do mundo: a vida de Eric Hobsbawm*
}

\section{The best-known historian in the world: the life of Eric Hobsbawm}

\author{
Resenha: EVANS, Richard J. Eric Hobsbawm: A Life in History. New York: Oxford University \\ Press, 2019, 785 p. \\ Palavras-chave: Eric Hobsbawm; Biografia; História Social. \\ Keywords: Eric Hobsbawm; Biography; Social History.

\section{Barbara Weinstein** Tradução: Antonio Luigi Negro***}

\begin{abstract}
$\triangle$ MAIORIA DE NÓs historiadoras e historiadores ficaria feliz de ter uma página da Wikipédia dedicada a si. Enquanto isso, Eric Hobsbawm não só publicou uma autobiografia em vida - aliás um best-seller -, como também é agora o tema de uma biografia de 750 páginas do ilustre historiador da Alemanha Richard J. Evans. Mesmo levando em conta que Hobsbawm, durante as últimas décadas de sua longa vida (1917-2012), foi possivelmente "o historiador mais conhecido e mais lido de todo o mundo", parece notável o tanto de material biográfico e autobiográfico publicado a respeito dele - isso para não mencionar o livro de memórias que vem aí, de Marlene Hobsbawm, sua viúva. Afinal das contas, não há maiores razões para se esperar que até mesmo a vida do mais eminente historiador consista em material de uma envolvente obra biográfica. Na verdade, como é observado por Evans no prefácio de Eric Hobsbawm: A Life in History, a autobiografia de Hobsbawm, Interesting Times (2002), era singularmente impessoal; dizia mais sobre a época em que ele viveu do que sobre si mesmo. Aparentemente, Evans avaliou que a vida merecia mais atenção, e o resultado é o livro aqui em tela.
\end{abstract}

\footnotetext{
* Resenha originalmente publicada na The American Historical Review, v. 125, n. 4, p. 1382-1385, out. 2020. DOI: https://doi.org/10.1093/ahr/rhaa208. Tradução publicada na Mundos do Trabalho, v. 13, 2021, com permissão da Oxford University Press.

** Doutora em História pela Yale University. Professora de História da América Latina e Caribenha na New York University. E-mail: bw52@nyu.edu. ORCID: https://orcid.org/0000-0002-1126-8622.

*** Doutor em História pela Universidade Estadual de Campinas (Unicamp). Professor Titular da Universidade Federal da Bahia (UFBA). E-mail: negro@ufba.br. ORCID: https://orcid.org/0000-0001-7253-355X.
} 
Certamente, um esboço em miniatura da vida de Hobsbawm comporta muitos dos elementos que associamos a um indivíduo digno de uma biografia. Nascido em 1917 em Alexandria, Egito, o jovem Eric logo se mudou para Viena com sua família britânico-judaica, ali passando a maior parte de sua infância. Na capital austríaca ele perdeu primeiro seu pai e, logo depois, sua querida mãe, de modo que, aos 14 anos, em tenra idade, Eric e sua irmã mais nova Nancy, agora órfãos, mudaram-se para Berlim a fim de morar com parentes próximos. Isso significa que Eric vivenciou o seu despertar político em tempo e lugar que testemunharam o desdobrar da maior catástrofe histórica do século XX. Felizmente para o jovem Hobsbawm, seus tios decidiram, na primavera de 1933, que era hora de voltarem para Londres, e assim Eric - que tinha sido apelidado de "o garoto inglês" em sua escola em Berlim - veio afinal a viver a vida na Grã-Bretanha, que serviria como sua principal residência até o fim. Um período socialmente difícil na escola secundária foi seguido por estudos universitários, com bolsa, em Cambridge, onde ficou conhecido como o calouro "que sabe de tudo". Depois do serviço militar, durante a Segunda Guerra Mundial, prosseguiu os seus estudos de doutorado em Cambridge, casou-se (sem sucesso), encontrou emprego estável em Birkbeck (Universidade de Londres), descobriu o amor pelo jazz e, a partir daí, cresceu gradualmente em influência e eminência no campo da História. Aos cinquenta, estava feliz no seu segundo casamento, sendo amplamente reconhecido como um dos principais historiadores da Grã-Bretanha.

Tudo até aqui parece um esboço razoavelmente promissor para um estudo biográfico, mas a verdade é que as experiências do dia a dia incorporadas a essa narrativa esquelética nem sempre são instigantes ou esclarecedoras. E você poderia perguntar "esclarecedora de quê?". Há algumas figuras cujas vidas têm tanto impacto sobre a História (Lincoln, Hitler, por exemplo) que esta pergunta praticamente já vem com a sua resposta. Mas com certeza Hobsbawm, apesar de ser um grande historiador, não era uma figura assim. O que, por conseguinte, estamos a procurar quando lemos (ou escrevemos) sua biografia?

Muita gente se senta com uma biografia em mãos simplesmente esperando por uma boa leitura. Algumas seções do livro, de fato, preenchem essa expectativa. Mas há muitos trechos onde Evans cai no que poderíamos chamar de "armadilha da biografia", quer dizer, a idéia de competir ao biógrafo fornecer o máximo de detalhes possíveis a fim de construir uma narrativa contínua que leve em conta todas as reviravoltas e guinadas da vida em questão, mesmo que não possuam nenhum interesse ou valor intrínseco. Assim, temos uma biografia com mais de 700 páginas, enquanto o primeiro sucesso de Hobsbawm, A era das revoluções, uma história das origens e do impacto da Revolução Francesa e da Revolução Industrial britânica, não vai além de menos de 400 páginas. A verdade é que seções substanciais de Eric Hobsbawm serão de grande interesse apenas para aqueles já fascinados pela cultura acadêmica britânica (e você sabe quem você é). Um gosto pelos detalhes granulares da política partidária britânica também pode ajudar. Quando o editor de suas memórias acusou 
Hobsbawm, por ter usado o termo descritivo "agradável", de soar "como Roy Jenkins", posso imaginar alguns leitores dando uma boa risada nessa hora. Só que eu não.

Ainda assim, quem lê com paciência eventualmente encontrará iluminação para duas perguntas que, eu suspeito, estarão na cabeça da maioria dos historiadores que irão mergulhar nesse livro. Uma me vem por ser óbvia: o que fez de Hobsbawm um historiador tão bem-sucedido e ilustre? A outra é a pergunta irritante: por que ele continuou sendo um membro (quase) vitalício do Partido Comunista da Grã-Bretanha? Fazendo a segunda pergunta antes, perdi a conta do número de vezes que Evans assegurou a quem o lê que Hobsbawm, tanto como historiador quanto como pensador político, jamais foi inflexível ou dogmático. Pode-se dizer que o autor faz juras demais, exceto pelo fato de Evans dispor amplas evidências do gosto intelectual eclético de Hobsbawm e seu apreço pela obra de colegas que não compartilhavam sua inclinação pela análise marxista. E à medida que Hobsbawm se tornava, mais e mais, um intelectual público, defendendo posições políticas que refletiam uma visão pragmática da esquerda e do Partido Trabalhista, a sua filiação ao PCGB parecia, igualmente, cada vez mais simbólica ou afetiva, em vez de ideológica. Evans cita Hobsbawm por afirmar, em várias passagens, que as circunstâncias da sua adesão inicial - a luta contra o nazismo em Berlim - contavam para a continuidade de sua perseverante lealdade ao comunismo. Também é fácil imaginar como o partido se tornou uma espécie de lar para uma criança sem mãe, para um jovem brilhante, cujas origens e laços familiares tinham sido abruptamente rompidos. Assim, o que eu achei mais notável não foi sua teimosa insistência em manter a filiação formal ao partido, mas os implacáveis interrogatórios inquiridores de todo tipo sobre o seu compromisso, aparentemente irracional, com o comunismo. Era como se nada mais sobre Hobsbawm fosse realmente digno de exame, o que certamente não é o caso, embora eu não esteja persuadida de ser preciso mais de 700 páginas para ter certeza disso.

Como Evans demonstra, a decisão de Hobsbawm de permanecer no partido até o amargo fim teve um custo somado à repetitiva pauta de entrevistadores sem imaginação. Embora os professores universitários britânicos de esquerda nunca tenham passado pelas angústias sofridas pelos seus colegas nos EUA sob o macartismo, Hobsbawm viu-se repetidamente frustrado por gente, em posição de autoridade, que se contrariava com sua filiação política ou sua abordagem marxista das questões históricas. Sua primeira experiência nesta linha aconteceu no decorrer do serviço militar, quando, apesar de ser bilíngue em alemão e inglês e razoavelmente fluente em várias outras línguas, foi repetidamente deixado de lado em missões, devido a preocupações com sua lealdade ideológica. Embora não tenha deixado de ser uma irritação relativamente menor no contexto de um mundo em guerra, suspeito que muitos leitores poderão se chocar quando lerem os relatos sobre a obstrução às tentativas de Hobsbawm de ter sua(s) tese(s) de doutorado aceita(s) ou seus primeiros artigos aprovados para publicação, com as típicas objeções de um desdém pelo materialismo histórico. Depois disso tudo, houve ainda o caso - lamentável - do chefe do Departamento 
de História da Birkbeck, que jurou impedir Hobsbawm de ser promovido a professor titular, com base principalmente em objeções ideológicas. E mais: incrivelmente, Evans é capaz de reproduzir as conversas - palavra por palavra - dos anos 1930 e 1940, diálogos em que Eric está falando, ou sendo referido, porque a espionagem britânica plantou microfones na sede do Partido Comunista, tendo depois arquivado as transcrições dessas escutas.

Evans detalha as maneiras pelas quais o pendor de Hobsbawm para a análise marxista e sua recusa em abandonar suas anteriores simpatias pelo comunismo dificultaram sua carreira profissional. Porém, antes de qualquer coisa, o que ele não considera - embora seja evidente para mim - é a forma como sua visão marxista da história tornou possível a brilhante carreira de Hobsbawm. Falar várias línguas e "saber tudo" são atributos úteis para um historiador, mas posso facilmente imaginar um estudioso com essas qualidades escrevendo obras de História pedantes ou tão abrangentes a ponto de serem virtualmente ilegíveis. O que parece crucial é a forma pela qual sua atenção contínua à classe e à ascensão do capitalismo proporcionou um panorama que lhe permitiu percorrer grandes extensões de terrenos históricos - conflitos políticos, crises econômicas, inovações artísticas, lutas sociais - sem perder o foco.

Por causa disso, fiquei um tanto desapontada com a falha do autor em explorar em profundidade as razões que fizeram de livros como The Age of Revolution (1962) um grandioso sucesso. ${ }^{1}$ Evans faz uma excelente discussão sobre The Age of Extremes (1994), tanto sua elaboração quanto sua recepção, mas quando este último volume da série " $A$ era do" apareceu, Eric Hobsbawm já havia se tornado um historiador de fama mundial. ${ }^{2} \mathrm{Em}$ outras palavras, é difícil separar com nitidez de contraste o sucesso desse volume de sua notoriedade pré-existente. Diferentemente, $A$ era das revoluções brilhou exatamente quando Hobsbawm ainda se encontrava numa fase relativamente inicial de sua carreira. Colocar lado a lado uma revolução política, a francesa, e outra econômica, a industrial, foi uma cartada inteligente, mas não parece suficiente para explicar por que o livro foi um sucesso logo de cara, abrindo caminho para mais três volumes ( $A$ era do capital, $A$ era dos impérios, Era dos extremos). Em grande parte da biografia, Evans parece mais ansioso em nos fornecer pormenores das negociações de Hobsbawm acerca dos adiantamentos do livro e dos créditos dos direitos autorais. Assim, parece menos interessado em responder à minha pergunta - que eu considero ser "a" pergunta - sobre o que fez de Hobsbawm um historiador tão grande e tão amplamente celebrado.

Evans empreendeu a tarefa de escrever a biografia de Hobsbawm como alguém que estudou seu assunto por muitos anos, nutrindo clara admiração, quer intelectual quer pessoal. Além disso, ele contou com total colaboração de Marlene Hobsbawm e outros membros da família, recebendo acesso direto aos volumosos documentos pessoais de Hobsbawm. Portanto, não se trata de um livro que "tira tudo de dentro do armário" biográfico de Hobsbawm,

$1 \quad$ N.T.: No Brasil, é de 1977 a primeira edição de $A$ era das revoluções.

2 N.T.: No Brasil, é de 1995 a primeira edição de Era dos extremos. A tradução do livro contou com a revisão técnica de Maria Célia Paoli, cuja tese de doutorado foi orientada por Hobsbawm. 
mas Evans não se esquiva de discutir algumas das falhas e pontos cegos do seu sujeito como historiador. Um deles foi o seu eurocentrismo sem prurido; não só fez da Europa Ocidental o foco dos seus livros mais importantes, mas, sim, o fez porque via a Grã-Bretanha e a França, em particular, como os principais geradores das cruciais mudanças que ocorreram no decorrer do que agora chamamos o longo século XIX. Sem chamadas para a escravidão ou o tráfico de escravos no índice, A era das revoluções traz apenas três breves menções a Saint-Domingue. Pode-se dizer que não é razoável esperar de alguém dessa geração atribuir à Revolução Haitiana o mesmo grau de significado que muitos historiadores fazem hoje, mas é interessante notar que o próprio Hobsbawm, escrevendo no início dos anos 1960, antecipou esta crítica, insistindo, no prefácio do livro, que, se deixava de mencionar países não impactados pelas duas revoluções em questão, "naturalmente, isto não significa que as histórias dos países e povos negligenciados (...) sejam menos interessantes ou importantes do que as que estão incluídas". Não estou inteiramente convencida de que ele realmente pensasse assim, mas não deixa de impressionar vê-lo se sentindo obrigado a fazer esse registro.

Se uma perspectiva marxista clássica sobre classe social e a mudança histórica fundamentavam o eurocentrismo de Hobsbawm, ela era ainda mais evidente na sua incursão tardia e um tanto desajeitada pela História das mulheres. Evans discute em detalhe a resposta altamente crítica ao capítulo de The Age of Empire (1987) sobre "A nova mulher", no qual Hobsbawm (que antes havia omitido as mulheres e o gênero por completo) rejeitou - sem rodeios - o feminismo, como um movimento burguês incapaz de gerar mudanças históricas genuínas. ${ }^{3}$ Vários dos principais historiadores britânicos de mulheres (incluindo duas que tinham feito sua tese de doutorado sob a orientação de Hobsbawm) o repreenderam por sua abordagem insensível e antiquada quanto às mulheres e ao gênero. É difícil saber se ele levou a crítica muito a sério, mas pelo menos dedicou quantidade considerável de espaço às mulheres e ao feminismo no The Age of Extremes.

Talvez o mais surpreendente para mim, com respeito à prática histórica de Hobsbawm, seja sua limitada interação com arquivos. Até onde sei, uma vez concluída a pesquisa de doutorado, ele mal pôs os pés em um arquivo. Ele lia com voracidade e isso foi fator do mais importante para conseguir escrever sínteses tão convincentes de épocas históricas. Mas parece ter sido imune ao fascínio dos arquivos. Em sua autobiografia, ele faz referência a um financiamento recebido em 1962 da Fundação Rockefeller "a fim de investigar sobre o objeto de pesquisa" de seu livro então recente, Primitive Rebels (1959). A julgar pelo próprio relato de Hobsbawm e pela biografia de Evans, "investigar" significava encontrar-se com intelectuais importantes num determinado local e se inteirar das fontes impressas, em vez de se aventurar em arquivos. É possível perceber que, para Hobsbawm, livros como Primitive Rebels e Bandits (1969) tinham caráter ensaístico; não eram definitivos. ${ }^{4}$ Ambos os livros têm sido alvo

3 N.T.: No Brasil, é de 1988 a primeira edição de $A$ era dos impérios.

4 N.T.: No Brasil, é de 1970 a primeira edição de Rebeldes primitivos. Bandidos é de 1975. 
de críticas frontais por parte de estudiosos cujos estudos de caso refletem um envolvimento mais intenso com material arquivístico e fontes orais, mas isso não parece ter incomodado o seu autor, que os viu como uma forma de abrir uma conversa - um ponto que não escapou aos eminentes especialistas que recomendam a leitura na contracapa da primeira edição de Primitive Rebels e que, na verdade, referem o livro como um roteiro para pesquisas futuras. Numa linha muito menos simpática, a nêmesis de Hobsbawm no Departamento de História de Birkbeck, R. R. Darlington, se valeu da ausência de fontes manuscritas no trabalho de Hobsbawm como justificativa para rejeitar sua promoção na carreira de professor.

Em contraste, fontes manuscritas abundam mesmo em Eric Hobsbawm, a biografia. No caso de Evans, talvez o principal desafio tenha sido de escrever sobre alguém que, num passado recente, tinha publicado sua própria autobiografia. Em Interestings Times, Hobsbawm deu a conhecer a sua identidade como um intelectual cosmopolita, como alguém que viajava para destinos diversos ou distantes, na trama de uma vasta rede de amigos e conhecidos. ${ }^{5}$ A biografia de Evans, pelo contrário, é mais insular, tanto no sentido literal quanto no figurativo. Apesar de relatar as constantes excursões de seu sujeito por França, Itália, Brasil, Nova York, é principalmente a história do "garoto inglês", ou seja, trata-se de um relato sobre os percursos de Eric Hobsbawm na academia britânica e, secundariamente, na política britânica de esquerda. Isso pode ser em parte devido à necessidade de seguir um caminho distinto do percurso da autobiografia. Ou pode ser uma consequência das fontes disponíveis para Evans, ou pode simplesmente ser devido ao modo como o autor imaginava Hobsbawm. Nem sempre é a leitura mais cativante - aqui e ali, senti como se um subtítulo apropriado para o livro fosse Tempos ordinários -, mas acho que nos dá uma perspectiva da vida pessoal e profissional de Hobsbawm inexistente em suas memórias, e creio ser instrutiva sobre a história do pequeno mundo habitado pela maioria das leitoras e leitores de revistas acadêmicas.

Evans também faz justiça às muitas, e às vezes contraditórias, facetas da persona de Eric Hobsbawm. É difícil - e provavelmente impreciso - pensar em alguém tão eminente e erudito como sendo um sujeito "pé no chão", mas o biografado parece ter sinceramente admirado as pessoas cujas habilidades e interesses eram bem diferentes de si. Ele era um ávido fã de jazz, chegou a escrever um livro de ensaios sobre o tema, usando pseudônimo, mas adorava música clássica também. Da mesma forma, ele lia uma enorme variedade de textos refinados, o que é algo de se esperar de alguém da sua envergadura, quer históricos, quer filosóficos. Mas também era um fã do gênero policial. Foi obstinado ao persistir na condição de filiado ao Partido Comunista, mas também evidentemente desfrutou das várias honras que lhe foram concedidas pelas instituições britânicas tradicionais (ele, no entanto, recusou a nomeação de cavalheiro; "sir Eric" era ir longe demais).

Ainda me resta intrigante, porém, a relação de Hobsbawm com sua identidade judaica, especialmente no tocante ao Holocausto, quase totalmente intocado tanto na autobiografia

5 N.T.: No Brasil, é de 2002 a primeira edição de Tempos interessantes. 
quanto na biografia. Evans cita a observação de uma grande amiga de Hobsbawm - "não estava nada interessado no Shoah" - e em seguida explica a coisa como uma decorrência da "visão global abrangente" de Hobsbawm, o que o levou a ver os judeus como um grupo de vítimas dentre tantos, uma explicação que parece incompleta na melhor das hipóteses. No entanto, Evans observa que Hobsbawm carregou consigo, toda a sua vida, o conselho de sua mãe para nunca dizer ou fazer nada que pudesse levar as pessoas a acreditarem que ele tinha vergonha de ser judeu. Em sua autobiografia, Hobsbawm vê isso como o "fundamento duradouro" para sua identidade enquanto judeu, "apesar daqueles que não podem acreditar que um simples negativo pode ser uma base suficiente para a identidade".

Eric Hobsbawm viveu até a idade de 95 anos e, embora sua condição física tenha se deteriorado nos últimos anos, ele permaneceu lúcido até o final e inclusive conseguiu orquestrar o programa para o seu próprio funeral. Como era de se esperar, nas exéquias, o programa musical incluía tanto peças de jazz como de música clássica. As carpideiras leram uma série de textos seculares. Contudo, para surpresa de quem estava presente, Eric pedira a seu antigo colega da New School, Ira Katznelson, a récita do Kaddish, oração judaica do luto. $E$ então, talvez para garantir que ninguém concluísse que ele enfim se arrependia dos seus longos anos de apoio a uma particular visão da libertação humana, ele pediu que "A Internacional" fosse deixada para o fim.

Recebido em 01/04/2021

Aprovado em 15/04/2021 